\begin{abstract}
Iranica
Abstracta Iranica Revue bibliographique pour le domaine irano-aryen

Volume 34-35-36 | 2017

Comptes rendus des publications de 2011-2013
\end{abstract}

\title{
D. Stronach. Court Dress and Riding Dress at Persepolis: New Approaches to Old Questions
}

\section{Astrid Nunn}

\section{(2) OpenEdition}

1 Journals

\section{Édition électronique}

URL : http://journals.openedition.org/abstractairanica/41434

DOI : 10.4000/abstractairanica.41434

ISSN : 1961-960X

Éditeur :

CNRS (UMR 7528 Mondes iraniens et indiens), Éditions de l'IFRI

\section{Référence électronique}

Astrid Nunn, «D. Stronach. Court Dress and Riding Dress at Persepolis: New Approaches to Old Questions ", Abstracta Iranica [En ligne], Volume 34-35-36 | 2017, document 7, mis en ligne le 15 juillet 2016, consulté le 28 septembre 2020. URL : http://journals.openedition.org/abstractairanica/41434 ; DOI https://doi.org/10.4000/abstractairanica.41434

Ce document a été généré automatiquement le 28 septembre 2020.

Tous droits réservés 


\title{
D. Stronach. Court Dress and Riding Dress at Persepolis: New Approaches to old Questions
}

\author{
Astrid Nunn
}

\section{RÉFÉRENCE}

D. Stronach. « Court Dress and Riding Dress at Persepolis: New Approaches to old Questions », in : Javier Álvarez-Mon, Mark B. Garrison, eds., Elam and Persia. Winona Lake, Eisenbrauns, 2011, p. 475-487.

1 La question de savoir si les deux vêtements différents, celui volumineux et celui plus serré, dont les représentations sur les reliefs des escaliers de l'Apadana de Darius I Ir $^{\text {à }}$ Persépolis apparaissent en nombre égal, possèdent chacun une fonction, a souvent été abordée. En s'appuyant sur les textes et sur certains témoins iconographiques (le relief d'Aspathines à Naqš-e Rostam et les porteurs d'armes des reliefs de Persépolis) qui représentent des hommes en vêtement lisse, l'A. réitère la thèse selon laquelle la robe volumineuse à amples manches serait un "court dress", alors que le vêtement beaucoup plus serré et lisse serait un "riding dress". Les porteurs du vêtement lisse ne sont pas des Mèdes, comme on le dit généralement, mais des Perses achéménides. 


\section{AUTEURS}

\section{ASTRID NUNN}

Université de Munich 